\title{
Temporal and Spatial Variations in Macrofouling of Silicone Fouling-release Coatings
}

\author{
CHRISTINA DARKANGELO WOOD ${ }^{1, *}$, KATHRYN TRUBY $^{1}$, JUDITH STEIN ${ }^{1}$, \\ DEBORAH WIEBE ${ }^{2}$, ERIC HOLM ${ }^{3}$, DEAN WENDT $^{4}$, CELIA SMITH $^{4}$, \\ CHRISTOPHER KAVANAGH ${ }^{5}$, JEAN MONTEMARANO ${ }^{3}$, GEOFF SWAIN $^{5}$ and ANNE MEYER ${ }^{6}$ \\ ${ }^{1}$ GE Corporate Research and Development, K1-4A54, One Research Circle, Niskayuna, NY 12309, USA; \\ ${ }^{2}$ Bridger Scientific, Bourne, MA 02532, USA; ${ }^{3}$ NSWCCD, Bethesda, MD 20084, USA. \\ ${ }^{4}$ University of Hawaii, Honolulu, HI 96813, USA, ${ }^{5}$ Florida Institute of Technology, Melbourne, FL 32901, USA; \\ ${ }^{6}$ University at Buffalo, Buffalo, NY 14214, USA
}

Nontoxic, low surface free energy silicone coatings having reduced biofouling adhesion strength have been developed as an alternative to antifouling paints. Silicone coatings permit macrofouling to adhere; however, fouling can be removed easily by water pressure or light scrubbing. One of the current methods used to evaluate the performance of non-toxic silicone foulingrelease coatings relies heavily on fouling coverage. The organismal community structure as well as total coverage can affect the ease of fouling removal from these coatings. This paper explores fouling coverage and organismal adhesion over time. Long-term fouling coverage data were collected at four sites (in Massachusetts, Hawaii and Florida) using static immersion panels coated with silicone and oil-amended silicone systems. Inter-site differences in fouling coverage and community structure were observed for each coating. Intra-site variation and temporal change in coverage of fouling was minimal, regardless of coating formulation. The extent of coverage was affected by the duration of immersion and the local environmental conditions; these factors may also have an impact on the foul-release capability of the silicone coatings. Organismal adhesion data was collected in Hawaii and Florida. These adhesion measurements were used as a tool to discriminate and rank fouling release coatings.
Keywords: fouling release; coatings; silicone; coverage; barnacle adhesion; tubeworm adhesion; oyster adhesion

\section{INTRODUCTION}

Biofouling is ubiquitous in the aquatic environment. Fouling on the hulls of marine vessels has been shown to reduce maximum speed and increase propulsive fuel consumption (Haslbeck \& Bohlander, 1997). Traditional antifouling paints containing toxic triorganotin compounds or cupric oxide are highly effective in controlling the fouling (Bleile \& Rodgers, 1989). Due to environmental concerns, however, the application of triorganotin-based paints has been prohibited on smaller vessels $(<25 \mathrm{~m})$ and it is expected that the use of cupric oxide paints will be limited in the near future (Walker, 1998). In response to environmental concerns, non toxic marine coating alternatives have been developed. Silicone fouling-release coatings are one of several non-toxic 
alternatives to toxic, antifouling coatings that have been developed over the past 22 years (Callow \& Fletcher, 1994 and references therein).

Toxic and non-toxic coatings control fouling in different ways. Toxic coatings do not become fouled until the end of their service life (Bleile \& Rodgers, 1989). Most non-toxic coatings, such as silicones, become fouled but rely on the "slipperiness" of their surfaces to release the fouling after settlement. Fouling coverage on silicone coatings is usually less than the coverage on other nontoxic surfaces (Callow et al., 1988; Watermann et al., 1997; Swain et al., 1998). Most macrofouling may be removed from silicone coatings by a water spray or light brushing (Callow et al., 1988; Meyer et al., 1994; Swain \& Schultz, 1996).

Because of the mode of action of fouling-release coatings, their testing and evaluation requires additional test methods to discriminate coating performance. Adhesion strength of macrofouling organisms has been shown to be useful in distinguishing between the fouling-release capabilities of various silicone coatings (Callow et al., 1988; Swain et al., 1992). The silicone coatings discussed in this paper were evaluated using fouling coverage, barnacle adhesion strength measurements (Swain et al., 1994) as well as oyster and tubeworm adhesion strength measurements.

In this work, results are reported on the temporal and spatial variation in coverage by macrofouling, and the adhesion strengths of organisms attached to two non-toxic silicone coatings.

\section{MATERIALS AND METHODS}

\section{Experimental Design}

Two silicone test coatings were exposed at multiple static immersion sites, and the total percentage cover and coverage of specific organismal groups were recorded over time. This was necessary since the physical, chemical, and biological characteristics of the local marine environment affect the type of macrofouling organisms that settle and the pattern of their settlement in space and time. Exposing coatings at multiple test sites provided for testing under varying environmental conditions that could affect performance such as temperature, salinity, water flow, concentration of larvae, and pattern of larval settlement. The silicone test panels were made using the duplex fouling release coating system (Griffith, 1992) and experimental GE topcoats. The two silicone topcoats used in this study were RTV11 ${ }^{\circledR}$, a polydimethylsiloxane elastomer obtained from GE Silicones, and RTV11 ${ }^{\circledR}$ amended with 10 wt \% SF1154 ${ }^{(B)}$, a polydimethyldiphenylsiloxane oil also obtained from GE Silicones. The coatings were applied using a standard airless spray system. Two replicate panels were deployed and cumulative fouling coverage was monitored at each of four sites, viz. the University of Hawaii's Ford Island site (Pearl Harbor, Hawaii), Miami Marine Research and Testing Station (MMRTS; Biscayne Bay, Florida), and two sites in the northeastern United States (NE site MSS, and NE site BPS, estuarine sites located at the confluence of two rivers at the head of Narragansett Bay, Massachusetts). Organismal adhesion data were collected at Ford Island and at the Florida Institute of Technology (FIT) exposure platform in the Indian River Lagoon (Florida).

The cumulative coverage at all sites was monitored according to the standard method for testing of antifouling panels in shallow submergence (ASTM, 1978). The panels were inspected once a month or quarterly. The organismal adhesion measurements were obtained using the standard method for the barnacle adhesion strength in shear with slight modifications for oysters and tubeworms (ASTM, 1994).

\section{Test sites}

The test sites in this study were chosen for their variety of fouling organisms, temperature, and salinity conditions. At the Ford Island site, the major fouling organisms and their settlement 
TABLE I Generalized annual settlement of major fouling organisms at the Ford Island, Hawaii test site

\begin{tabular}{|c|c|c|c|c|c|c|c|c|c|c|c|c|}
\hline & $\mathrm{J}$ & F & $\mathbf{M}$ & A & $\mathbf{M}$ & $\mathrm{J}$ & $\mathrm{J}$ & A & $S$ & $\mathrm{O}$ & $N$ & $\mathrm{D}$ \\
\hline Barnacles & $x$ & $x$ & $x$ & & & & & & & & & $x$ \\
\hline Arborescent hydrozoans & & & & & & $x$ & $x$ & $x$ & $x$ & $x$ & & \\
\hline Sponges & $\times$ & & & & & $\times$ & $x$ & $x$ & $x$ & $x$ & $x$ & $x$ \\
\hline Colonial tunicates & $x$ & $x$ & $x$ & & & $x$ & $x$ & $x$ & $x$ & $x$ & $x$ & \\
\hline Sedimentary tubeworms & & & & $x$ & $x$ & $x$ & $x$ & $x$ & $x$ & $x$ & $x$ & $x$ \\
\hline Bivalve molluscs & $x$ & $x$ & $x$ & $x$ & $x$ & $x$ & $x$ & $x$ & $x$ & $x$ & $x$ & $x$ \\
\hline Calcareous tubeworms & $x$ & $x$ & $x$ & $x$ & $x$ & $x$ & $x$ & $x$ & $x$ & $x$ & $\times$ & $x$ \\
\hline Diatoms & $x$ & $x$ & $x$ & $x$ & $\times$ & $x$ & $x$ & $x$ & $x$ & $x$ & $x$ & $x$ \\
\hline
\end{tabular}

Data Courtesy of the University of Hawaii

TABLE II Generalized annual settlement of major fouling organisms at the northeastern (NE) test sites

\begin{tabular}{|c|c|c|c|c|c|c|c|c|c|c|c|c|}
\hline & $J$ & $\mathrm{~F}$ & M & $A$ & M & $J$ & $J$ & $A$ & $S$ & $\mathrm{O}$ & $\mathrm{N}$ & $\mathrm{D}$ \\
\hline Colonial ascidians & & & & & & & $x$ & $x$ & $x$ & $x$ & & \\
\hline Sessile tunicates & & & & & & & $x$ & $x$ & $x$ & & & \\
\hline Sponges & & & & & & $x$ & $x$ & & $x$ & $x$ & & \\
\hline Bryozoans & & & & & & $x$ & $x$ & $x$ & $x$ & $x$ & & \\
\hline \multicolumn{13}{|l|}{ Hydrozoans } \\
\hline Barnacles & & & & $x$ & $x$ & & & & $x$ & & & \\
\hline Bivalve molluscs & & & $x$ & $x$ & $x$ & & & & $x$ & $x$ & & \\
\hline Polychaetes & $x$ & $x$ & $x$ & $x$ & $x$ & $x$ & $x$ & $x$ & $x$ & $x$ & $x$ & $x$ \\
\hline
\end{tabular}

Data from Osman, 1977, taken at the Marine Biological Laboratory, Woods Hole, MA

periods were extrapolated from monthly settlement data on PVC panels (Table I). The data from Ford Island showed year-round settlement of diatoms, calcareous tubeworms, and bivalve molluscs and seasonal settlement of sedimentary tubeworms, colonial tunicates, sponges, and arborescent hydrozoans.

Temperature and salinity at the Ford Island site were relatively constant throughout the year and typical of a tropical marine environment. The average salinity ranged from $34-35 \%$ and the temperature ranged from $24-27^{\circ} \mathrm{C}$. The experimental coatings were immersed at this site in August 1997 and their monitoring is still underway.

In Biscayne Bay, a sub-tropical estuary, the major fouling organisms settled in organismspecific seasonal cycles. The community consisted primarily of barnacles, tunicates, encrusting bryozoans, hydrozoans, and sponges. At the MMRTS test area, salinity ranged from $34 \%$ in the spring to $20 \%$ in the summer and the temperature from $19^{\circ} \mathrm{C}$ to $30^{\circ} \mathrm{C}$ ("South Florida Ecosystem History Database" http://flaecohist.er.usgs.gov/
database/BBFieldTree.asp). The test panels were immersed at the Biscayne Bay site in December 1996 and are still under test.

Both of the northeastern test sites had similar fouling organisms and settlement cycles (Table II). Polychaete worms settled year-round. Fouling organisms that settled in the spring and summer included ascidians, tunicates, sponges, bryozoans, hydrozoans, barnacles, and bivalve molluscs. These sites are temperate estuaries; the temperature at both sites ranged from $4^{\circ} \mathrm{C}$ in the winter to $24^{\circ} \mathrm{C}$ in the summer. The annual salinity ranges at the two sites were different. The salinity at NE site BPS ranged from 25 to $30 \%$ and at NE site MSS ranged from 28 to $31 \%$; the salinity at NE site BPS was $4-5 \%$ higher and was more stable than NE site MSS throughout most of the year. The silicone-coated test panels were immersed at the northeastern sites in July 1997, but were cleaned back in December 1997. The coverage data reported in this paper were collected between March 1998 and March 1999 which represents a full year of accumulated coverage. 


\section{Measurement of Adhesion Strength}

Adhesion strength of selected macrofouling organisms was measured following ASTM (1994) or a slight modification thereof. A force gauge was used to record the shear force required to remove the organism from the surface of the coating. The contact area of each individual to the coating was calculated, and the resultant pressure to remove the organism was determined by dividing the shear force by the contact area (ASTM, 1994; Swain et al., 1994; Swain \& Shultz, 1996).

\section{RESULTS AND DISCUSSION}

\section{Fouling Coverage of Silicone Coatings at Four Sites}

Each exposure site had a different community of fouling organisms and different environmental conditions that may have affected coverage. The test panels at all sites were free from damage, delamination, or corrosion thoughout the duration of testing. Both the RTV11 ${ }^{\circledR}$ and the RTV11 ${ }^{\circledR}+10 \%$ SF1154 ${ }^{\circledR}$ coatings immersed at Ford Island (Hawaii) showed a steady increase in coverage of macrofouling organisms over the first 5 months of immersion (Figures 1,2). The coverage for both coatings reached a plateau between 75 and $85 \%$ of the coating surface, which was maintained for 1 year. The total coverage on both formulations consisted primarily of sponges and bivalve molluscs; other organisms were responsible for $<5 \%$ of the total coverage. The percentage of the surface of the panels that was fouled did not differ strongly between the two coating treatments (Analysis of Variance (ANOVA), $\mathrm{n}=8, p=0.140$ ).

In Biscayne Bay, Florida (MMRTS), the total coverage was comprised of a more diverse assemblage of organismal groups (Figures 3,4). The total coverage at MMRTS was less than the total coverage at Ford Island, and there was seasonal variation in coverage and community

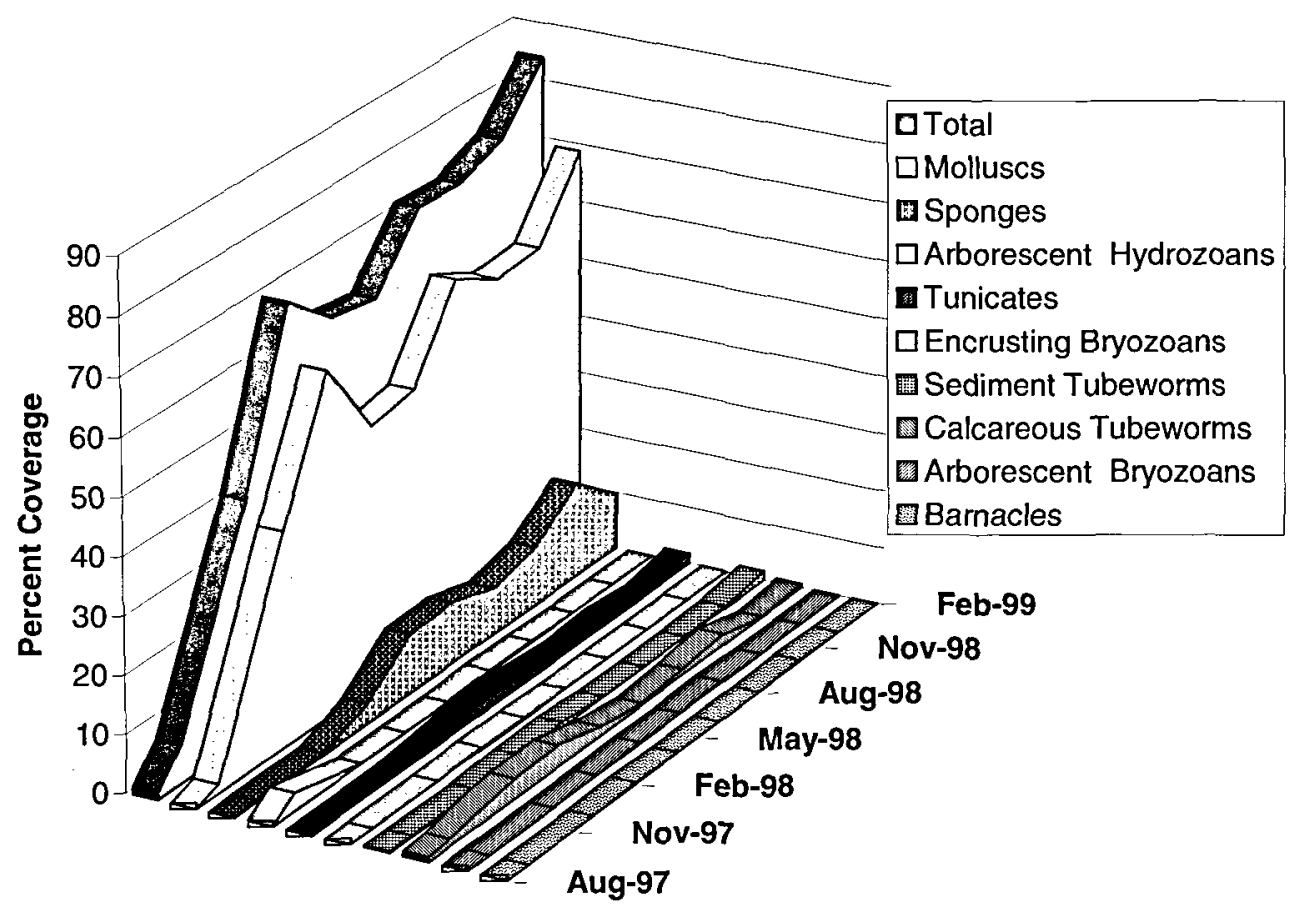

FIGURE 1 Average macrofouling coverage as a function of time and organismal group on four faces of two static immersion panels coated with RTV11 ${ }^{\circledR}$ at Ford Island, Hawaii. 


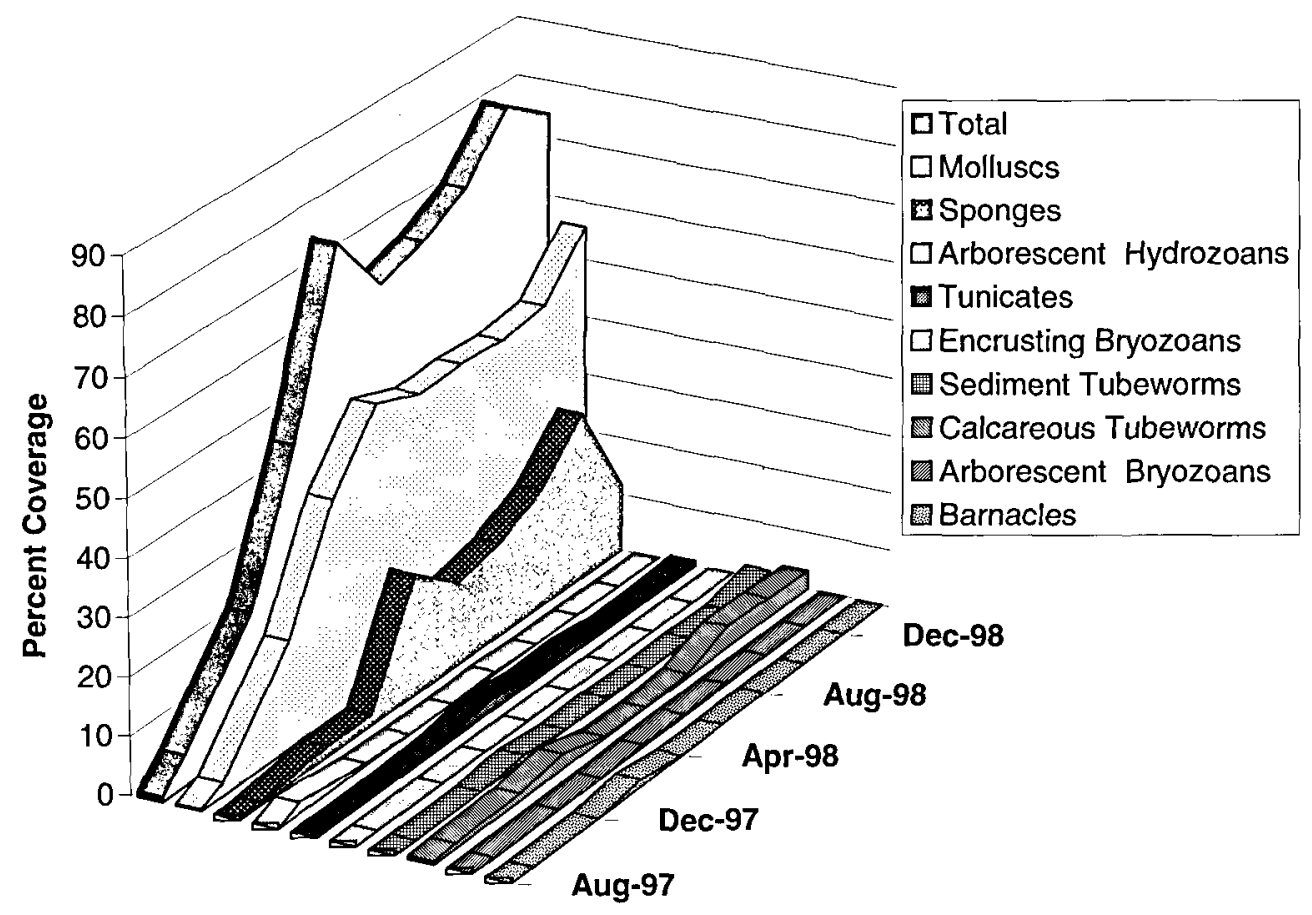

FIGURE 2 Average macrofouling coverage as a function of time and organismal group on four faces of two static immersion panels coated with RTV11 ${ }^{\circledR}+10 \%$ SF1154 $4^{\circledR}$ at Ford Island, Hawaii.

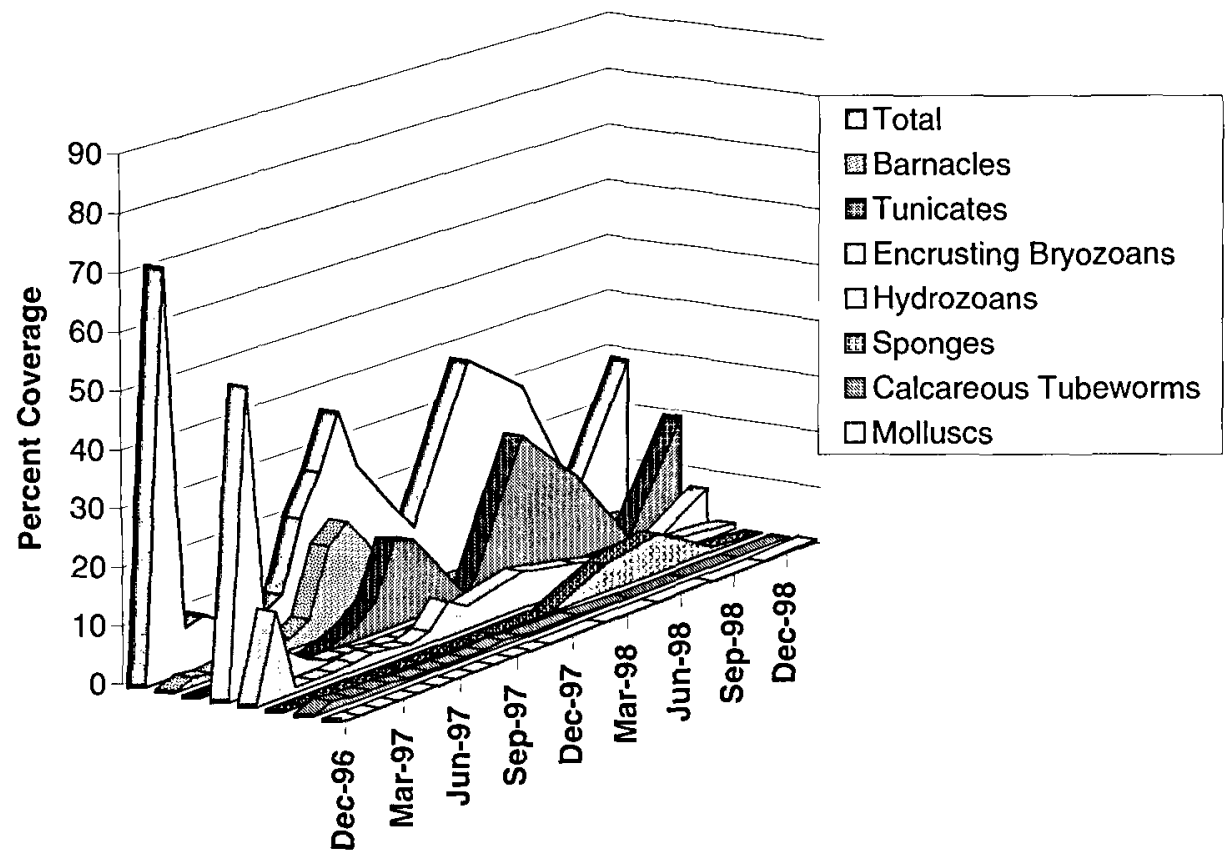

FIGURE 3 Average macrofouling coverage as a function of time and organismal group on two static immersion panels coated with RTV11 ${ }^{(*)}$ in Biscayne Bay, Florida. 


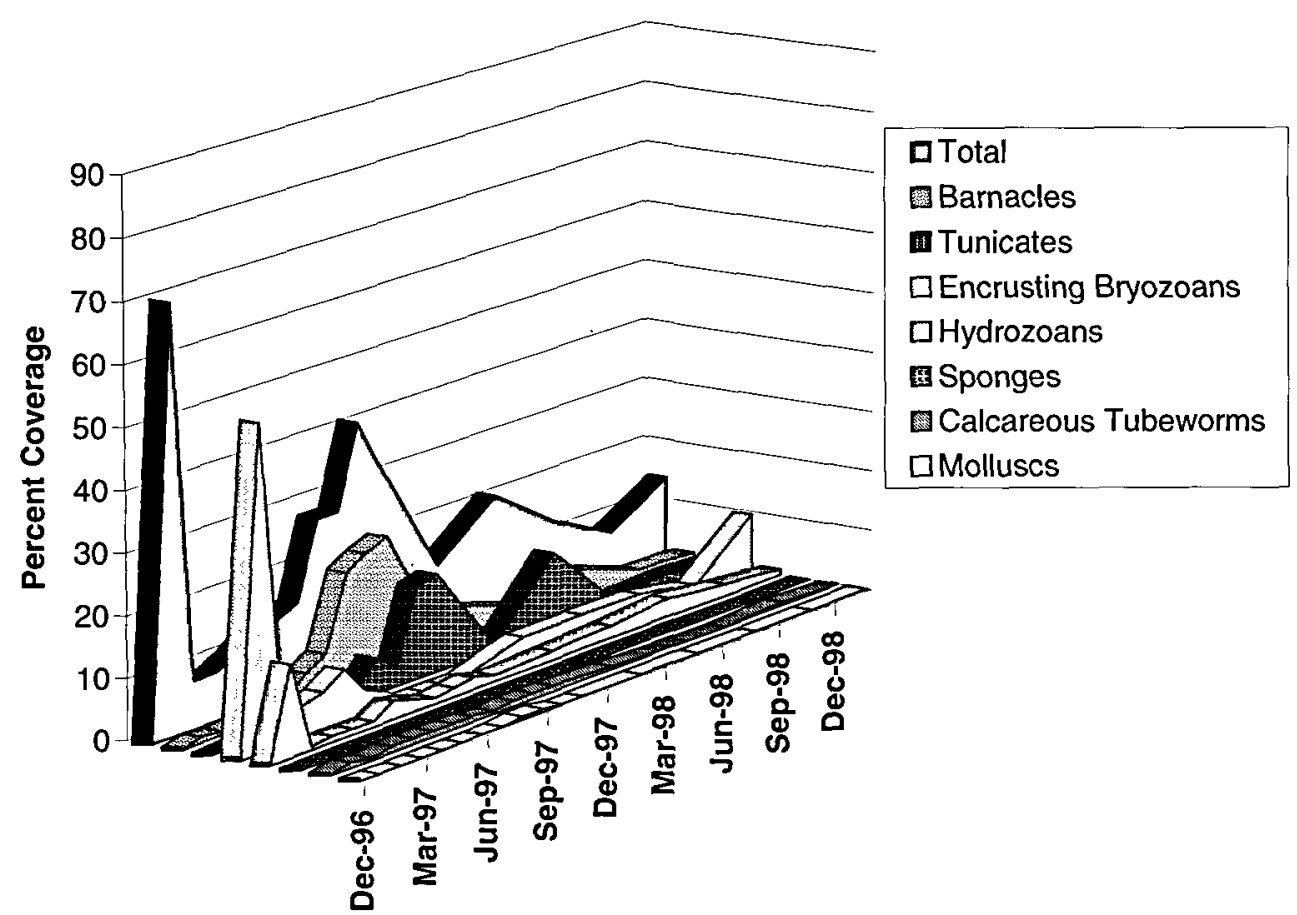

FIGURE 4 Average macrofouling coverage as a function of time and organismal group on two static immersion panels coated with RTV11 ${ }^{\mathbb{R}}+10 \%$ SF $1154^{*}$ in Biscayne Bay, Florida.

structure. These seasonal changes reflected the fouling season common in temperate regions. The cyclical pattern in coverage was more evident on RTV11 ${ }^{\circledR}$ than on RTV11 ${ }^{\circledR}+10 \%$ SF $1154^{\circledR}$ (Figures 3,4). Within the first month of immersion there was a large settlement of encrusting bryozoans on both panels sets. After this initial colonization the barnacles and tunicates became the dominant fouling types on these surfaces. At MMRTS, the percentage total coverage did not differ between the silicone formulations (ANOVA, $\mathrm{n}=4, p=0.340$ ).

Due to sampling artifacts, the fouling coverage data at the northeastern sites were grouped into organismal types; for example, encrusting bryozoans and tubeworms were combined into one organismal group. At NE site BPS, the total coverage on both coatings increased during the spring and summer seasons and decreased slightly over the winter (Figures 5, 6). Fouling coverage of RTV11 $^{\circledR}$ and the RTV11 ${ }^{\circledR}+10 \%$
SF1154 ${ }^{\circledR}$ was similar; the only notable differences in total coverage occurred between November 1998 and February 1999. The fouling on both formulations at NE site BPS was made-up of a diverse assemblage of the organismal types. The organismal type that had the greatest contribution to the fouling coverage was the tunicates/ "rubbery" bryozoans. The total coverage at NE site MSS on both silicone coatings was similar to that at NE site BPS, although the composition of the fouling community was different (Figures 7, 8). Fouling coverage consisted primarily of sponges/anemones and encrusting bryozoans/tubeworms. The cyclic pattern of settlement in the temperate regions was seen with peaks on both panels at NE site MSS in the late spring. Both of the silicone coating formulations at NE site MSS had similar coverage patterns over time. The NE immersion sites showed different seasonal coverage patterns and organismal composition of fouling coverage. 


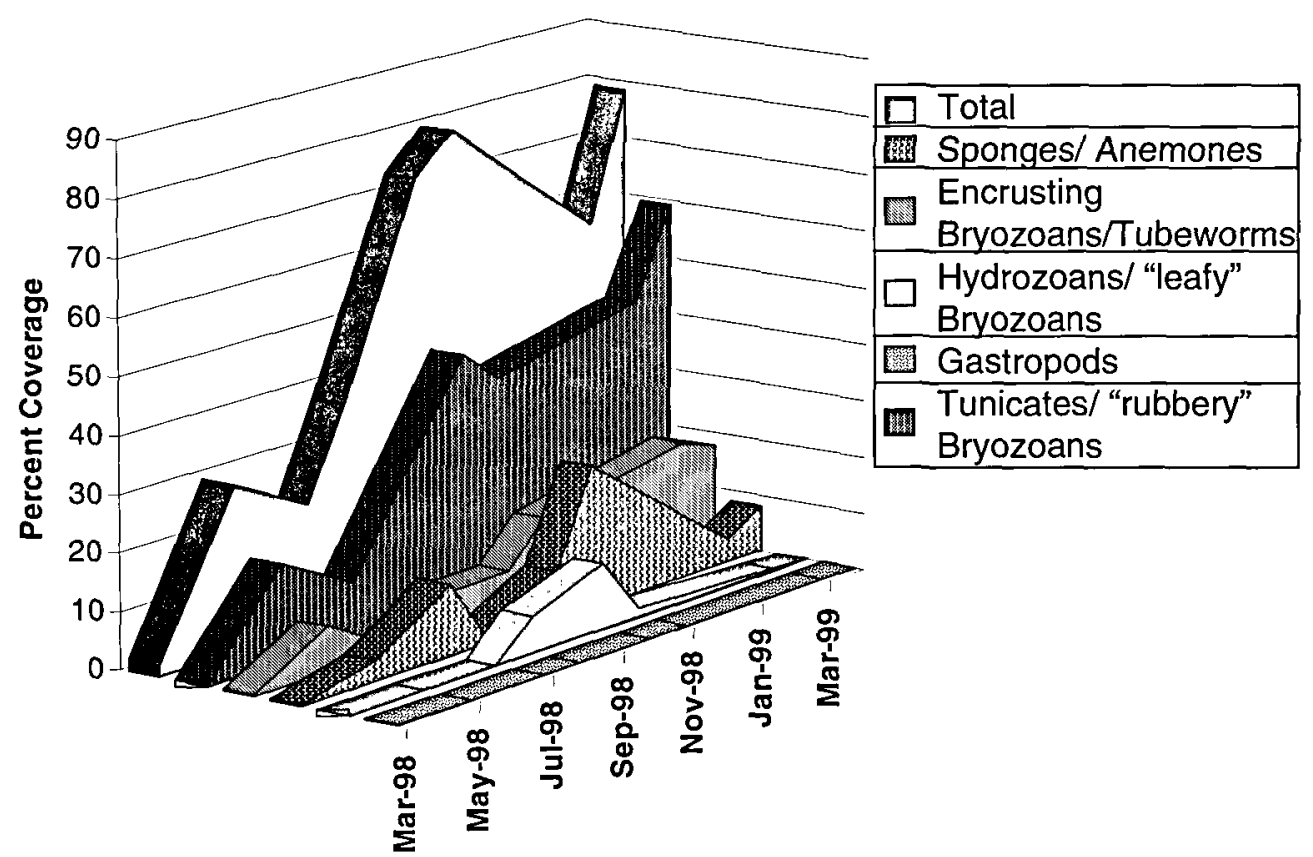

FIGURE 5 Average macrofouling coverage as a function of time and organismal group on two static immersion panels coated with RTV11 ${ }^{10}$ at NE site BPS.

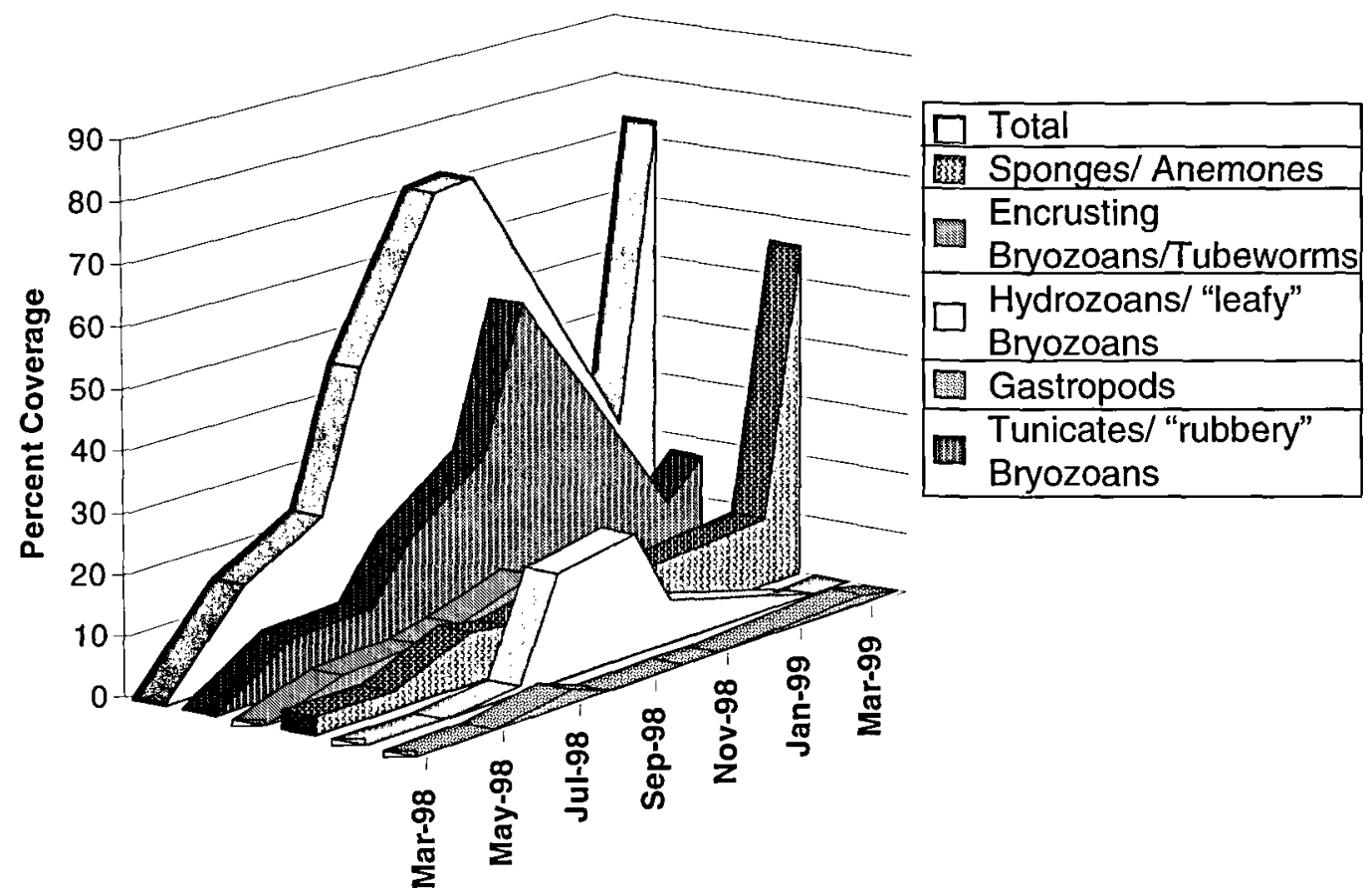

FIGURE 6 Average macrofouling coverage as a function of time and organismal group on two static immersion panels coated with RTV11 $+10 \%$ SF $1154^{(B)}$ at NE site BPS. 


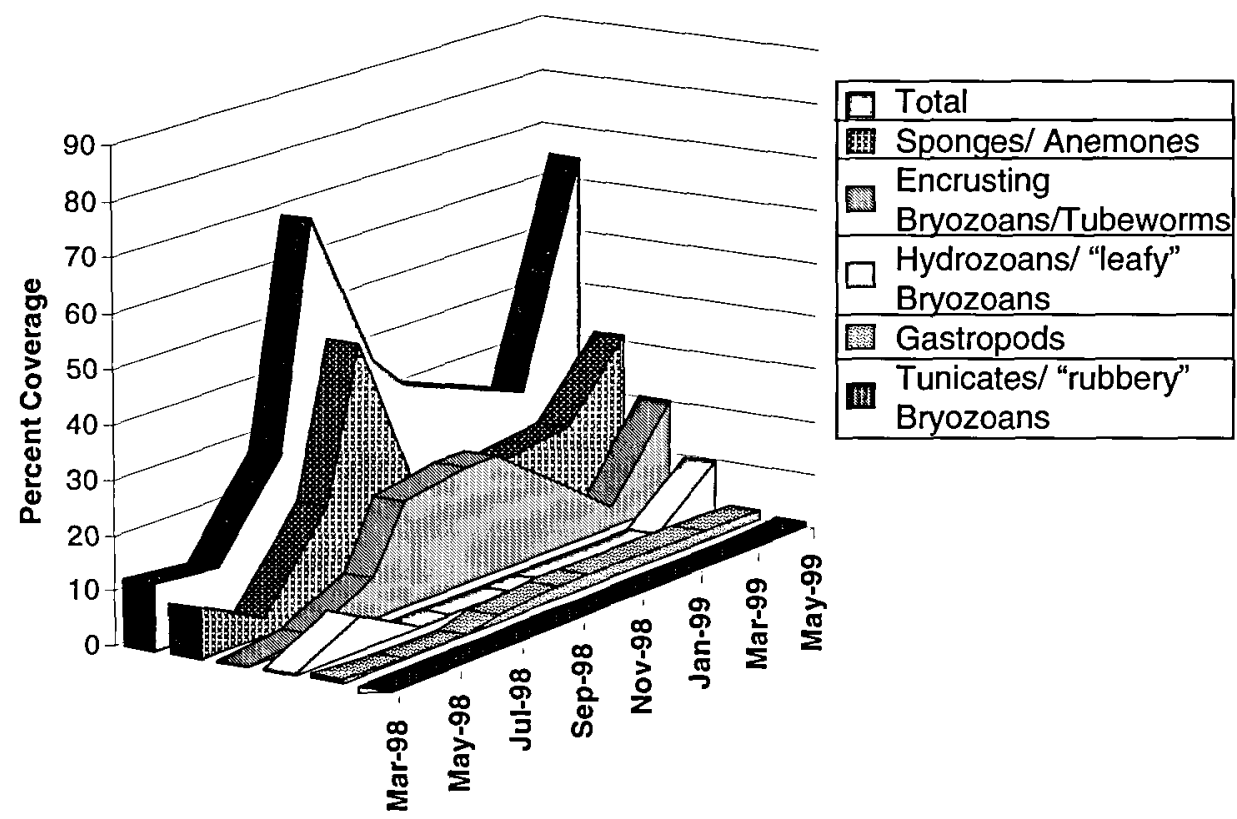

FIGURE 7 Average macrofouling coverage as a function of time and organismal group on two static immersion panels coated with RTV11 ${ }^{10}$ at NE site MSS.

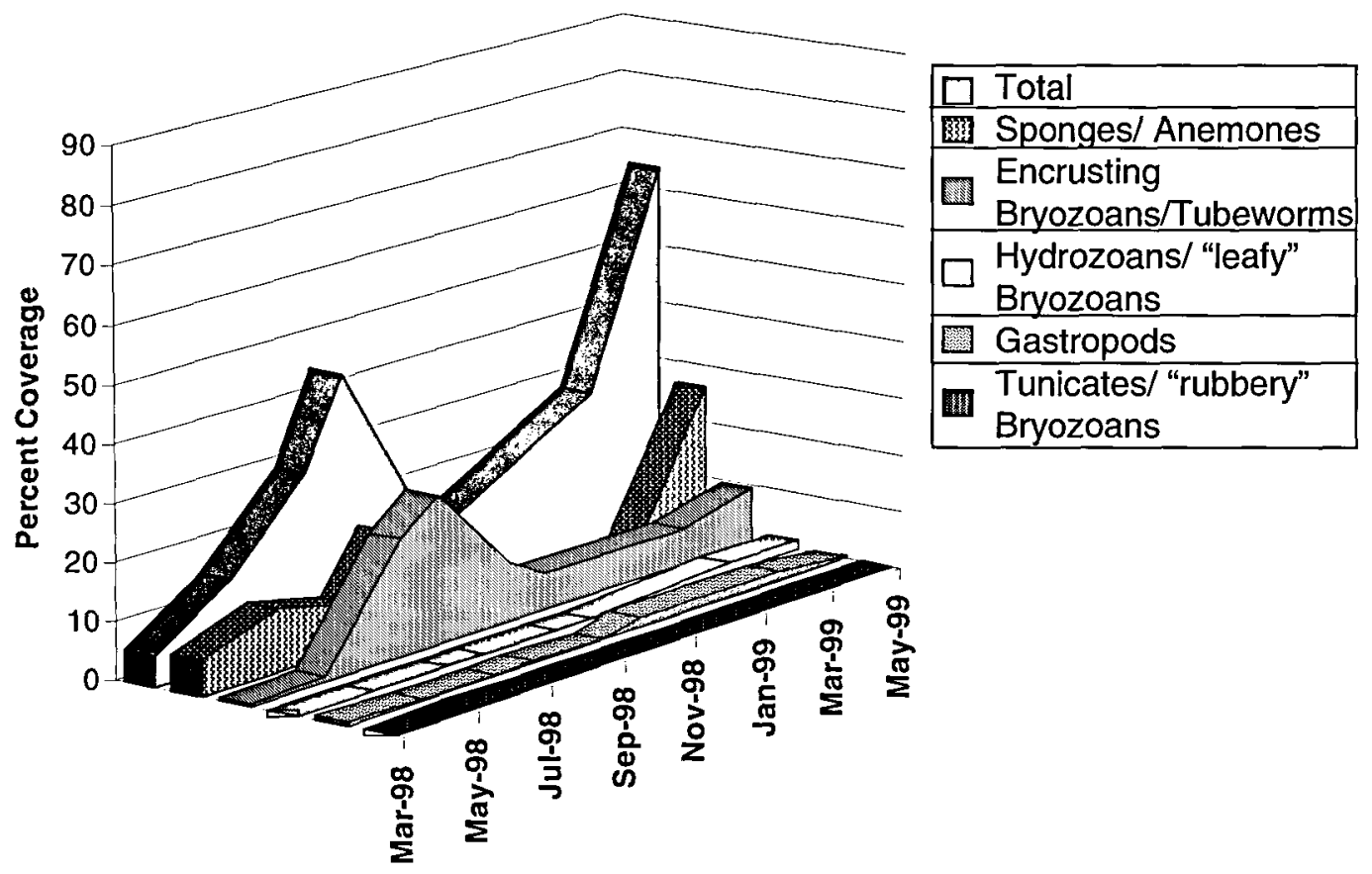

FIGURE 8 Average macrofouling coverage as a function of time and organismal group on two static immersion panels coated with RTV11 ${ }^{d}+10 \%$ SF $1154^{\text {ib }}$ at NE site MSS. 
Adhesion Strength of Oysters, Tubeworms, and Barnacles on Silicone Coatings at Two Exposure Sites

In Hawaii, oysters and tubeworms were abundant and colonized the test coatings in a quantity sufficient to make adhesion measurement possible. At the FIT site all primary hard fouling organisms (barnacles, tubeworms, and oysters) settled in sufficient quantities to allow for comparisons between coatings. All adhesion measurements were transformed using $(\ln (x+1))$ before statistical analyses were performed and an ANOVA analysis was used to discriminate statistically significant differences between coatings.

In Hawaii the adhesion strength of both oysters and tubeworms to RTV11 ${ }^{\circledR}+10 \% \mathrm{SF} 1154^{\circledR}$ was slightly less than the adhesion of those organisms to RTV11 ${ }^{\circledR}$ (Figure 9, Table III). This reduction in adhesion strength by the addition of oil was not statistically significant (oysters, $n=48, p=0.124$;

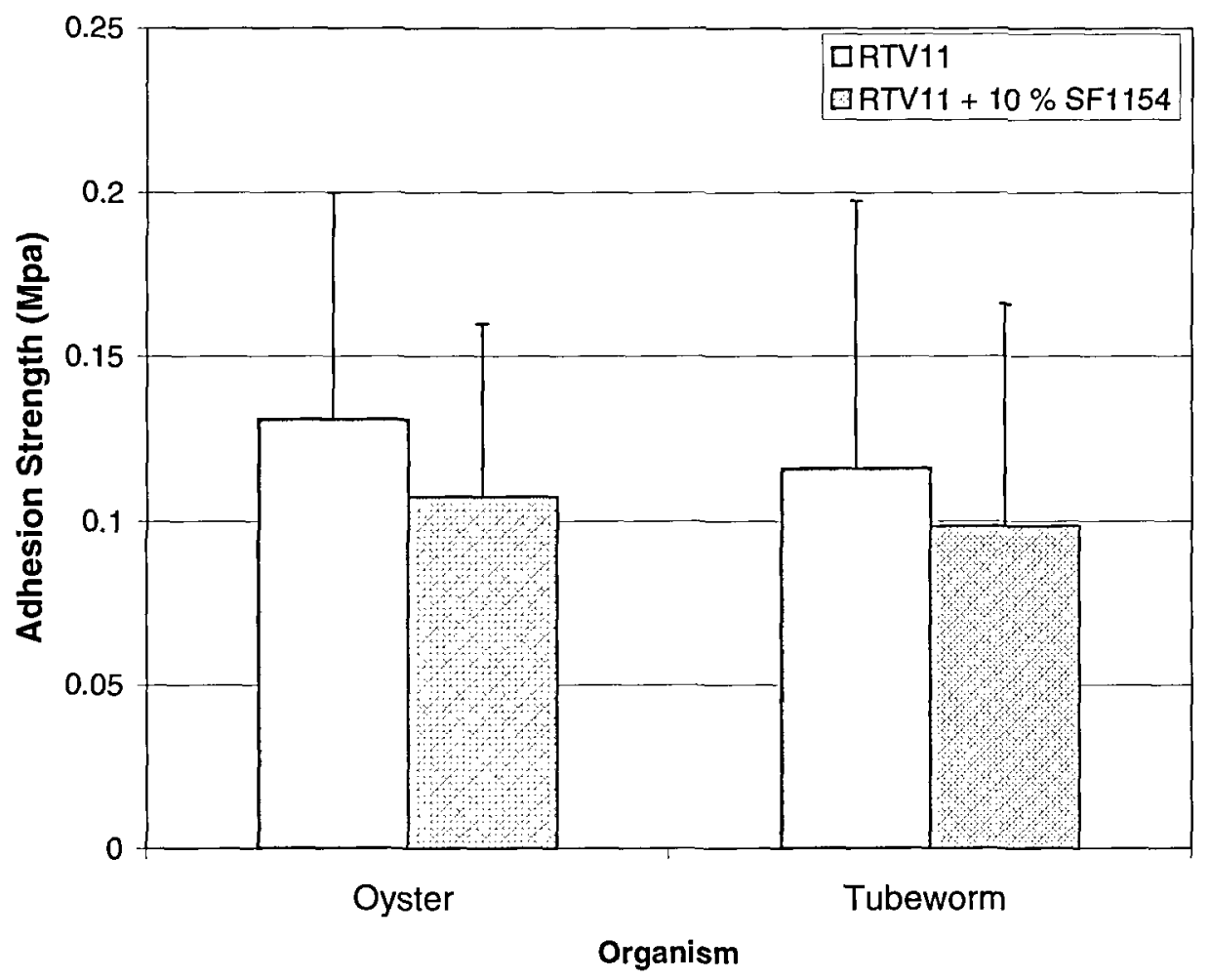

FIGURE 9 Average adhesion strength, in Mpa, of oysters and tubeworms on RTV11 ( $\square$ ) and RTV11 + 10\% SF1154 () at the Hawaii test site. Error bars = one SD.

TABLE III Summary of average adhesion strength (+SD), in Mpa, at the Hawaii and Florida test sites

\begin{tabular}{lcccc}
\hline Test coating & Location & Balanus eburneus & Oyster & Tubeworm \\
\hline RTV11 & Hawaii & & $0.131 \pm 0.069$ & $0.116 \pm 0.081$ \\
RTV11 +10\% SF1154 & Hawaii & & $0.107 \pm 0.052$ & $0.098 \pm 0.067$ \\
RTV11 & FIT & $0.067 \pm 0.031$ & $0.103 \pm 0.045$ & $0.097 \pm 0.025$ \\
RTV11 +10\% SF1154 & FIT & $0.043 \pm 0.020$ & $0.060 \pm 0.020$ & $0.095 \pm 0.026$ \\
\hline
\end{tabular}


tubeworms, $\mathbf{n}=34$, and $p=0.835$ ). In Florida, the adhesion of barnacles and oysters were significantly decreased by the addition of oil to the silicone topcoat (barnacles, $\mathrm{n}=572, p=0.000$; oysters, $\mathrm{n}=19, p=0.021$ ), while the adhesion of tubeworms was unaffected by the incorporation of oil (tubeworms $n=43, p=0.734$ ) (Figure 10, Table III).

In order to determine the temporal variation in adhesion strengths of macrofouling organisms on the two coatings, a regression analysis was performed. Adhesion measurements (Mpa) were transformed $(\ln (x+1))$ in order to meet assumptions for the regression analysis. There were insufficient numbers of observations to permit regression analyses for barnacles on either coating in Hawaii or for oysters on RTV11 ${ }^{\circledR}$ in Florida. The side and number of panel from which each adhesion measurement was taken were considered when evaluating the regression analysis. No panel or side relationship was found for any organisms on either coating. At FIT there was no statistical evidence of a change in barnacle, tubeworm, or oyster adhesion over time on the RTV11 ${ }^{\circledR}+10 \%$ SF1154 ${ }^{\circledR}$ (barnacles $\mathrm{n}=215$, $p=0.146$, oysters $\mathrm{n}=17, p=0.647$, tubeworms $\mathrm{n}=18, p=0.534)$. The adhesion strengths of barnacles and tubeworms on RTV11 ${ }^{\circledR}$ at FIT also showed no change over time (barnacles $n=316$, $p=0.654$, tubeworms $n=26, p=0.278$ ). At the Hawaii site there was a slight decrease in the adhesion strength of oysters with time with a slope of -0.001 on RTV11 ${ }^{\circledR}(\mathrm{n}=30, p=0.019)$ and RTV11 $^{\circledR}+10 \%$ SF1154 ${ }^{\circledR}(\mathrm{n}=28, p=0.046)$. Tubeworms on RTV11 ${ }^{\mathbb{R}}$ in Hawaii showed a statistically significant increase in adhesion strength with time with a slope of $0.003(n=23, p=0.000)$ (Figure 11).

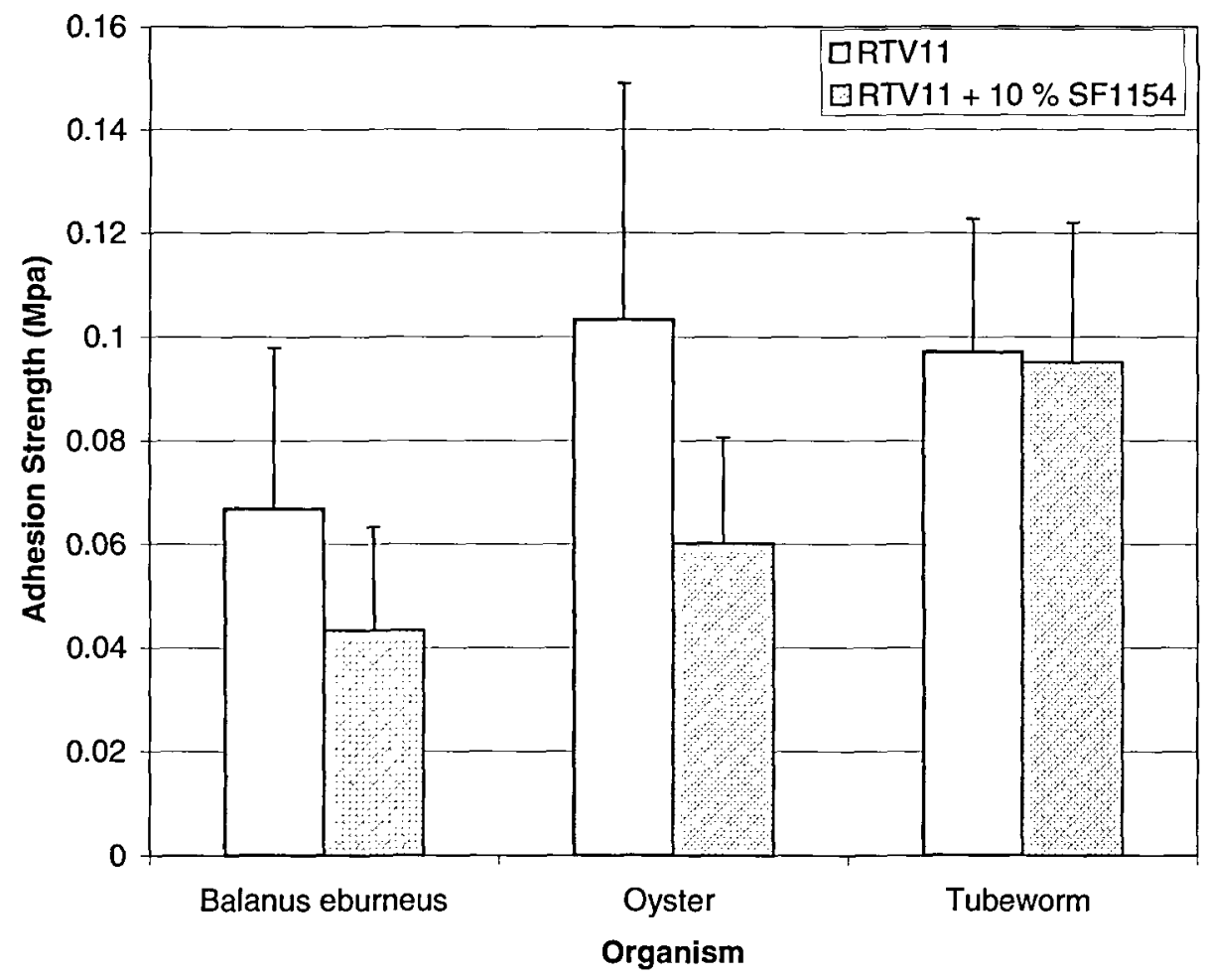

FIGURE 10 Average adhesion strength, in Mpa, of barnacles (B. eburneus), oysters, and tubeworms on RTV11 (D) and RTV11 + 10\% SF1154 (G) at the Florida test site. Error bars = one SD. 


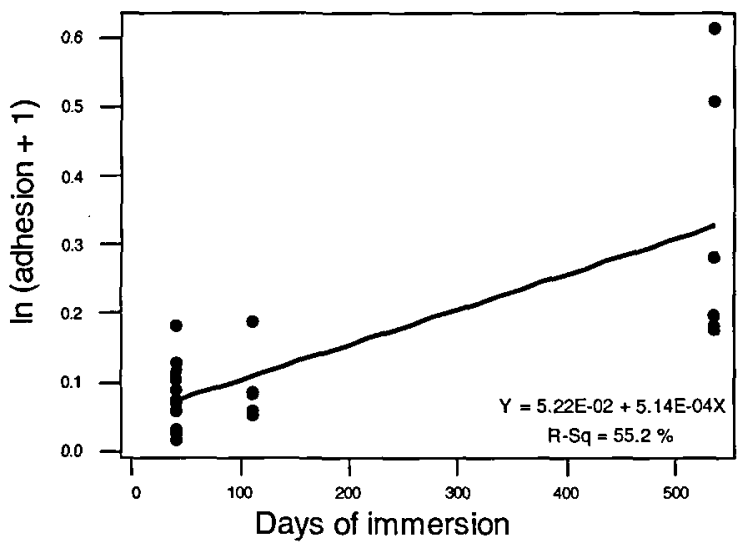

FIGURE 11 Regression analysis of the $\ln (x+1)$ transform of tubeworm adhesion on RTV11 showed an increase in adhesion strength with time.

\section{CONCLUSIONS}

Non-toxic silicone fouling release coatings were exposed to aquatic environments for $1 \frac{1}{2}-2$ years at three North American sites and at Hawaii. The types and abundances of fouling organisms differed at each site, but no significant differences in total coverage were seen between the two coating formulations at any given site. Inter-site differences in fouling coverage were seen, even at test sites in the same geographical area. The differences that were observed among the sites may be attributed to the differences in the fouling environment at each site.

Adhesion measurements on the silicone coatings demonstrated that oil incorporation decreases barnacle and oyster adhesion in Florida. Oyster and tubeworm adhesion in Hawaii was not affected by the incorporation of oil. There was no significant change in adhesion strength of hard fouling organisms over time at either Florida or Hawaii on oil containing silicone coatings. However, at Hawaii, the adhesion strength of tubeworms on the coating without free oil increased over time. These results imply that the coating with oil could be a preferable long term solution to reduce tubeworm adhesion.

\section{Acknowledgments}

This work was supported by DARPA contract N00014-96-C0145. Our sincerest thanks go to Owen Harblin, Dr James Cella, Dr Martha Gardner, Carlos Perez, Dr Hal Guard, and Dr Steve Wax for their support and contribution to this project and B Nedved and $\mathrm{K}$ De Anglelis who assisted with collection of the fouling and adhesion data from the Ford Island, Hawaii site.

\section{References}

ASTM D3623 (1978) Standard method for testing antifouling panels in shallow submergence. American Standard for Testing and Materials, Marine Coatings. 06.02

ASTM D5618 (1994) Standard method for measurement of barnacle adhesion strength in shear. American Standard for Testing and Materials, Marine Coatings, 06.02

Bleile H R, Rodgers S (1989) Marine coatings: In: Brezinski D, Miranda T J (eds) Federation Series on Coatings Techno$\log y$. Federation of Societies for Coating Technology, Philadelphia, pp 14-28

Callow M E, Fletcher R L (1994) The influence of low surface energy materials on bioadhesion - a review. Int Biodeterior and Biodegrad 133: 333-348

Callow M E, Pitchers R A, Santos R (1988) Non-biocidal antifouling coatings. In: Houghton $\mathrm{D} R$, Smith $\mathrm{R} N$, Eggins HOW (eds) Biodeterioration 7. Elsevier Applied Science, Oxford, pp 43-48

Griffith J (1992) Nontoxic marine antifouling coatings. US patent 847401

Haslbeck E, Bohlander G (1997) Hydrodynamic drag evaluation of antifouling coatings - laboratory and field. Proc Emerging Nonmetallic Materials for the Marine Environment 1: 45-51

Meyer A E, Baier R E, Forsberg R L (1994) Field trials of nontoxic fouling-release coatings. Proc $4^{\text {th }}$ Int Zebra Mussel Conf, Report No TR-104029. Electric Power Research Institute, Palo Alto, CA, pp 273-290

Osman R W (1977) The establishment and development of a marine epifaunal community. Ecol Monogr 47: 37-63

Swain G W, Schultz M P (1996) The testing and evaluation of non-toxic antifouling coatings. Biofouling 10: 187-197

Swain G W, Schultz M P, Vincent H L (1994) Shear force measurements of barnacle adhesion for field evaluation of non-toxic foul-release surfaces. In: Thompson M F, Nagabhushanam R, Sarojini R, Fingerman $M$ (eds) Recent Developments in Biofouling Control. Oxford and IBH, New Delhi (India), pp 335-341

Swain G W, Nelson W G, Preedeekanit S (1998) The influence of biofouling adhesion and biotic disturbance on the 
development of fouling communities on non-toxic surfaces. Biofouling 12: 257-269

Swain GW, Griffith J R, Bultman D, Vincent H L (1992) The use of barnacle adhesion measurements for the field evaluation of non-toxic foul release surfaces. Biofouling 6: 105-114
Walker I (1998) Non-toxic fouling control systems. Pitture Vernici Eur 13: 17-22

Watermann B, Berger H-D, Sönnichsen H, Willemsen P (1997) Performance and effectiveness of non-stick coatings in seawater. Biofouling 11: 101-118 